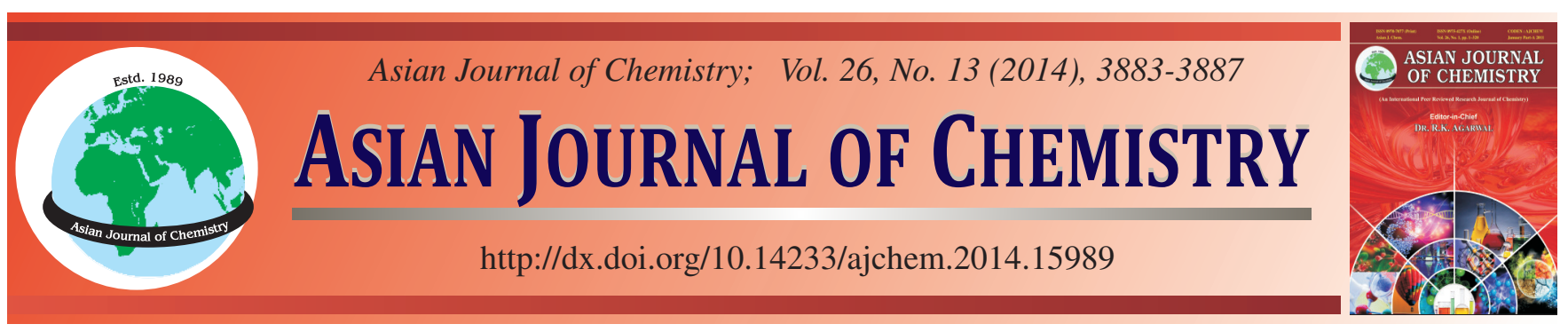

\title{
Preconcentration of Synthetic Phenolic Antioxidants in Instant Noodle Samples by \\ Alcohol-Based Vortext-Assisted Liquid-Liquid Microextraction and Determination by High-Performance Liquid Chromatography
}

\author{
Chang LiU ${ }^{1}$, Ye LiU $^{2}$, YANG JiaO ${ }^{3}, \mathrm{Li} \mathrm{BI}^{1}$ and Yaling YANG ${ }^{1, *}$
}

${ }^{1}$ Faculty of Life Science and technology, Kunming University of Science and Technology, Kunming 650105, Yunnan Province, P.R. China ${ }^{2}$ Yunnan Salt Chemical Co., Ltd. Kunming 560300, Yunnan Province, P.R. China

${ }^{3}$ Engineering Department, University of Wisconsin-Milwaukee, Milwaukee, WI 53211, USA

*Corresponding author: Tel: +86 13888316388; E-mail: yilyil8@163.com

In this work, a novel method termed as vortext-assisted liquid-liquid microextraction (VALLME) combining high performance liquid chromatography with diode array detection (HPLC-DAD) was developed for the determination of synthetic phenolic antioxidants in instant noodle samples. The isobutanol was used as extractant and the vortex-mix was utilized to reduce extraction time and improve extraction efficiency. Under the function of vortex-mix, it is favorable for the mass transfer of the analytes from the aqueous sample to the extraction solvent. Parameters affecting the extraction efficiency were systematically investigated. Under the optimal conditions, the spiked recoveries for analytes were in the range of 89.5-110.5\% and the limits of detection (LOD) for all target analytes were in range of 1.5 to $6.4 \mu \mathrm{g} \mathrm{L} \mathrm{L}^{-1}(\mathrm{~S} / \mathrm{N}=3)$. The experimental results indicated that the proposed procedure was successfully applied to the determination of synthetic phenolic antioxidants in instant noodle samples.

Keywords: Vortext-assisted liquid-liquid microextraction, HPLC, Instant noodle, Synthetic phenolic antioxidants, Isobutanol.

\section{INTRODUCTION}

Many synthetic compounds, which are characterized by a good antioxidant activity and are easily available, have been used in a wide variety of food products. These synthetic antioxidants include mainly phenolic compounds i.e., butylated hydroxyanisole (BHA), butylated hydroxytoluene (BHT), octyl gallates (OG), nordihydroguaiaretic acid (NDGA) and tert-butyl hydroquinone (TBHQ). Due to their low cost, highperformance and wide availabilities, these substances are frequently used in the feedstuffs and food ${ }^{1}$. Antioxidants are used to delay oxidative rancidity, thus reducing the loss of nutritional quality and increasing the shelf life of a wide variety of lipid-containing foods (such as instant noodles). Antioxidants act by interrupting the chain reaction responsible for producing peroxides, by passivating the free radicals, ceding hydrogen and become stabilized by resonance. Normally, synthetic antioxidants are polyphenolic compounds that are more or less liposoluble and suspected of being responsible for liver damage and carcinogenesis ${ }^{2}$, usually at concentrations up to $100-200 \mu \mathrm{g} \mathrm{g}^{-1}$ in foods, either singly or in combination ${ }^{3}$.

As for the analysis step, the best available methods for synthetic phenolic antioxidants are high-performance liquid chromatography with diode array detector (HPLC-DAD). Reversed-phase HPLC provides high selectivity for the separation of synthetic antioxidants under chromatographic conditions ${ }^{4-5}$. Other methods including thin-layer chromatography (TLC) $)^{6}$, gas chromatography $(\mathrm{GC})^{7}, \mathrm{GC}^{-} \mathrm{MS}^{8,9}$, gas liquid chromatography $(\mathrm{GLC})^{10}$, micellar electrokinetic capillary chromatography ${ }^{11}$ and spectrophotometry ${ }^{12}$ have also been used for determination of synthetic phenolic antioxidants.

With the development of the detecting techniques, an appropriate pretreatment method prior to chromatographic analysis has become more and more important. Liquid-liquid extraction (LLE) is the oldest and widely used extraction method for the analysis of synthetic phenolic antioxidants ${ }^{13}$. However, it is tedious and unfriendly to both the environment and operators. Other methods such as solid phase extraction $(\mathrm{SPE})^{14}$, solid-phase microextraction $(\mathrm{SPME})^{15}$ and stir bar sorptive extraction (SBSE) ${ }^{16}$ can be quite expensive.

In 2006, a member of the family of liquid phase microextraction techniques known as dispersive liquid-liquid microextraction (DLLME) has been introduced by the research group of Assadi ${ }^{17}$ and has been coupled to many analytical techniques. DLLME were applied for extraction of different compounds from aqueous matrices ${ }^{18-19}$. However, this method 
is not very suitable for extraction of compounds from solid samples.

Similarly, the homogeneous liquid-liquid microextraction (HLLME) is composed of the extracting and the 'auxiliary means' and the sample. It is based on the same principle of DLLME, but avoiding the use of the disperser solvent, the use of vortex agitation has been proposed in the so-called vortexassisted liquid-liquid microextraction (VALLME) by Yiantzi et $a l .{ }^{20}$. In this study, vortex-assisted act as an auxiliary means was performed in the course of VALLME. In the VALLME, the extraction solvent was dispersed freely into aqueous sample by the function of vortex mixing. The fine droplets formed and analytes could be rapidly extracted from aqueous phase since the shorter diffusion distance and larger specific surface area. After centrifugation the enrichment phase is diluted by methanol and ready for instrumental analysis. The enrichment factor can be reached ${ }^{25}$. Unlike the conventional DLLME is the use of density solvent such as chlorinated solvents as extractant and is incompatible with liquid chromatography, extractant cannot be injected directly to LC system for analysis. Isobutanol is used as an extractant, whose polarity is similar with the analytes and extraction solvent can directly inject to HPLC. Naturally, the extraction efficiency of this method will be higher.

In the past, our laboratory has developed a method to determinate synthetic phenolic antioxidants based on cloud point extraction ${ }^{21}$. The objective of this work was to determine five synthetic phenolic antioxidants in instant noodles with the application of VALLME. The effects of various experimental parameters, such as the kind and volume of the extraction solvent, vortex time and $\mathrm{pH}$ were investigated and optimized. The developed VALLME overcomes several disadvantages of the former DLLME methods, while it maintains the advantages of them.

\section{EXPERIMENTAL}

Standards of tert-butyl hydroquinone (TBHQ) ( $\geq 99.0 \%$ ), nordihydroguaiaretic acid (NDGA) (> $95 \%$ ), butylated hydroxyanisole (BHA) $(\geq 98.5 \%)$, octyl gallates (OG) $(\geq$ $99.0 \%)$ and butylated hydroxytoluene (BHT) $(\geq 98 \%)$ were obtained from Sigma (St. Louis, Mo., U.S.A.). The structures of these synthetic phenolic antioxidants are shown in Fig. 1. A stock standard solution containing $1 \mathrm{mg} \mathrm{mL}^{-1}$ of synthetic phenolic antioxidants (TBHQ, NDGA, BHA, OG and BHT) were dissolved in methanol and stored in a freezer $\left(4{ }^{\circ} \mathrm{C}\right)$. Methanol was high-performance liquid chromatographic (HPLC) grade from Merck (Darmstadt, Germany). $n$-Butanol, isobutanol, 1-pentanol, $n$-hexanol, $n$-octanol and carbon tetrachloride were purchased from Kedi (Tianjin, China). 1-Butyl3-methylimidazolium tetrafluoroborate was purchased from Aladdin Chemistry (Co., Ltd. Shanghai, China). All other chemicals were of analytical reagent grade and used without further purification.

Chromatographic conditions: Chromatographic separation and evaluation were performed on an HPLC system (containing a vacuum degasser, an auto sampler, a quatpump and a diode-array detector; Agilent 1200 Series, Agilent Technologies, Calif., U.S.A.) equipped with a reversed phase C18 analytical column of $150 \times 4.6 \mathrm{~mm}$ (Agilent TC-C18). Quantification

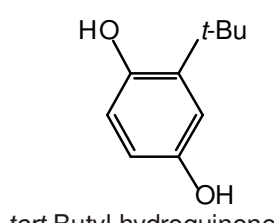

tert-Butyl hydroquinone (TBHQ)

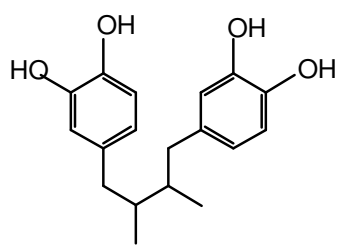

Nordihydroguaiaretic acid (NDGA)

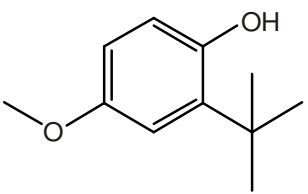

Butylated hydroxyanisole (BHA)

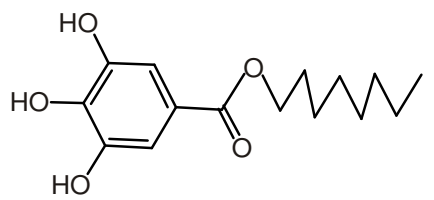

Octyl gallates (OG)<smiles>Cc1cc(C(C)(C)C)c(O)c(C(C)(C)C)c1</smiles>

Butylated hydroxytoluene (BHT)

Fig. 1. Molecular structures of TBHQ, NDGA, BHA, OG and BHT

was done by the evaluation of peak areas. Methanol (B) and water with $0.1 \%$ acetic acid (A) were used as mobile phase with the gradient program as follows: $50-85 \% \mathrm{~B}, 0-4.5 \mathrm{~min}$; 85-90 \% B, 4.5-6.5 min; 90-50\% B, 6.5-9.0 min. The flow rate was maintained at $1 \mathrm{~mL} \mathrm{~min}^{-1}$. The column temperature was maintained at $40^{\circ} \mathrm{C}$ and the injection volume was $10 \mu \mathrm{L}$. synthetic phenolic antioxidants were recorded at the wavelength of $280 \mathrm{~nm}$.

LB- $18^{\circ} \mathrm{C}$ ultrasonic (Shanghai Bilang instrument factory, Shanghai, China) and vortex agitator (Shanghai Hanuo Instruments co., Ltd. Shanghai, China) were used to implement extraction procedure. A centrifuge (Shanghai surgical instrument factory, Shanghai, China) was used for complete phase separation.

Vortext-assisted liquid-liquid microextraction procedure: $0.6 \mathrm{~mL}$ of isobutanol as extraction solvent was added into the sample solution. The mixtures were diluted with doubly distilled water to $5 \mathrm{~mL}$ and adjusted the $\mathrm{pH} 5$ by $1 \mathrm{~mL}$ of phosphate buffer solution (PBS) in the meantime. The tube was vigorously shaken on a vortex agitator for $30 \mathrm{~s}$. A cloudy solution (aqueous samples and isobutanol) was formed during the vortex process. Then the centrifuge tube was centrifuged at the speed of 3000 rpm for $5 \mathrm{~min}$ and the organic phase was floats in the test tube. After that, the upper solution was withdrawn by microsyringe and achieved a final volume of $0.2 \mathrm{~mL}$ by adding methanol. At last, $10 \mu \mathrm{L}$ were injected into HPLC system.

Samples: Instant noodle samples from different companies were purchased from local supermarkets in Kunming city (China). All the instant noodles were crushed into powders. $1.25 \mathrm{~g}$ (dry weight) of the instant noodle sample was accurately weighed and ultrasonic processed in the presence of $10 \mathrm{~mL}$ of methanol at room temperature for $10 \mathrm{~min}$. The upper liquid phase was transferred into a $25 \mathrm{~mL}$ flask through a paper filter. The residue was extracted with another $10 \mathrm{~mL}$ of methanol once more and the supernatant was isolated and combined with the $1^{\text {st }}$ extraction fraction and diluted with doubly distilled 
water to the mark to form a $25 \mathrm{~g} \mathrm{~L}^{-1}$ sample solution. After filtering, aliquots $2 \mathrm{~mL}$ of the solution containing different concentrations of synthetic phenolic antioxidants (TBHQ, NDGA, BHA, OG and BHT) were placed in centrifugal tube for the VALLME.

\section{RESULTS AND DISCUSSION}

In this study the extraction efficiency in VALLME is affected by various parameters including: (i) the nature and the volume of extractant, (ii) the $\mathrm{pH}$ of the aqueous phase and (iii) the vortex time. Enrichment factor and extraction efficiency were used to evaluate the extraction effect under different conditions.

Selection of extractant: The selection of an appropriate extractant is an important factor in this investigation. The extractant must meet the following requirements: it should have a low solubility in water, good chromatographic behaviour and high extraction efficiency for the interested compound. Taking these considerations into account, six organic solvents including $n$-butanol, isobutanol, 1-pentanol, $n$-hexanol, $n$ octanol and carbon tetrachloride were examined as potential extractants for VALLME. The process was carried out by using $0.6 \mathrm{~mL}$ each of the extractant. According to the reports, the partitioning of analytes between the extractant and the aqueous solution depends largely on their solubilities in these two phases $^{22}$. The extraction efficiency of synthetic phenolic antioxidants using VALLME with different extraction solvents are shown in Fig. 2. As is evident in the figure, butanol showed better extraction recoveries for the target synthetic phenolic antioxidants. Several miscellaneous peaks were observed when 1 -pentanol and $n$-hexanol were used as the extraction solvent. Carbon tetrachloride is a traditional extraction solvent, but its efficiency for synthetic phenolic antioxidants was extremely low. Comparison of the extraction efficiencies obtained by $n$ butanol, $n$-octanol and isobutanol showed that isobutanol was the most efficient extraction solvents. So, isobutanol was selected in further study.

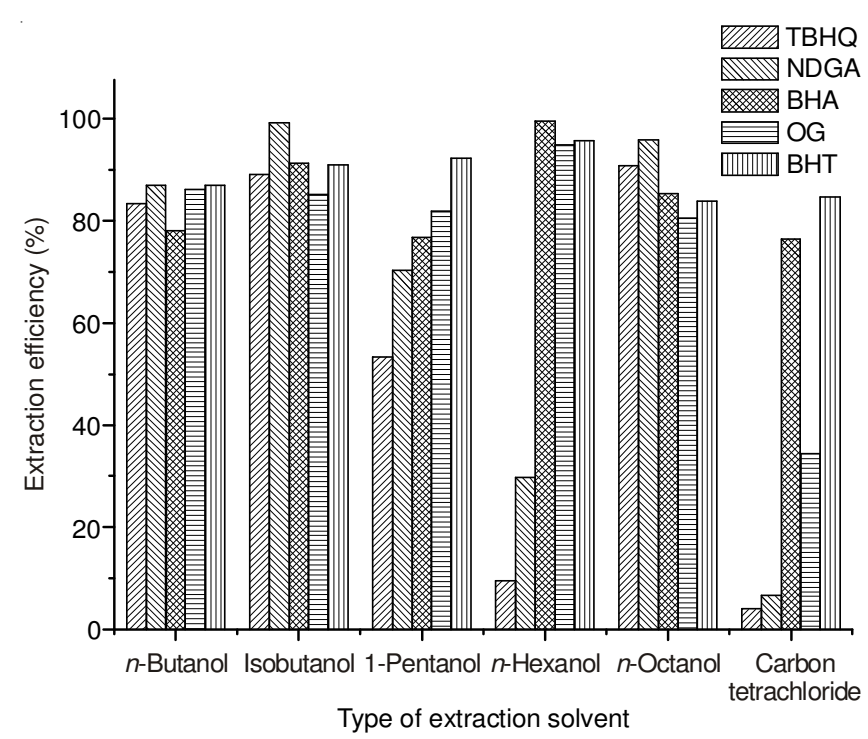

Fig. 2. Effect of different type of extraction solvent on the extraction efficiencies of synthetic phenolic antioxidants by VALLME. Extraction conditions: sample volume, $5.0 \mathrm{~mL}$; extraction solvent volume, $0.6 \mathrm{~mL}$; $\mathrm{pH}, 5.0$; vortex time, $30 \mathrm{~s}$
Extractant volume: The amount of extractant is another important factor that could affect the extraction efficiency and enrichment factor. To study the effect of extractant volume, different volumes $(0.4,0.6,0.8,1.0$ and $1.2 \mathrm{~mL})$ of isobutanol were investigated with the same VALLME procedure. With increasing the volume of isobutanol from 0.4 to $1.2 \mathrm{~mL}$, the volume of the rich phase increased from 0.05 to $0.8 \mathrm{~mL}$. Volume less than $0.4 \mathrm{~mL}$ was not investigated, because there is no phase separation formed. Fig. 3 shows that the signal obtained increases for an increase in the volume of the extractant and remains unchanged when reaches $0.6 \mathrm{~mL}$. Besides, the enrichment factor decreased sharply with the extractant volume ranging from 0.6 to $1.2 \mathrm{~mL}$. Therefore, the extractant volume was set at $0.6 \mathrm{~mL}$.

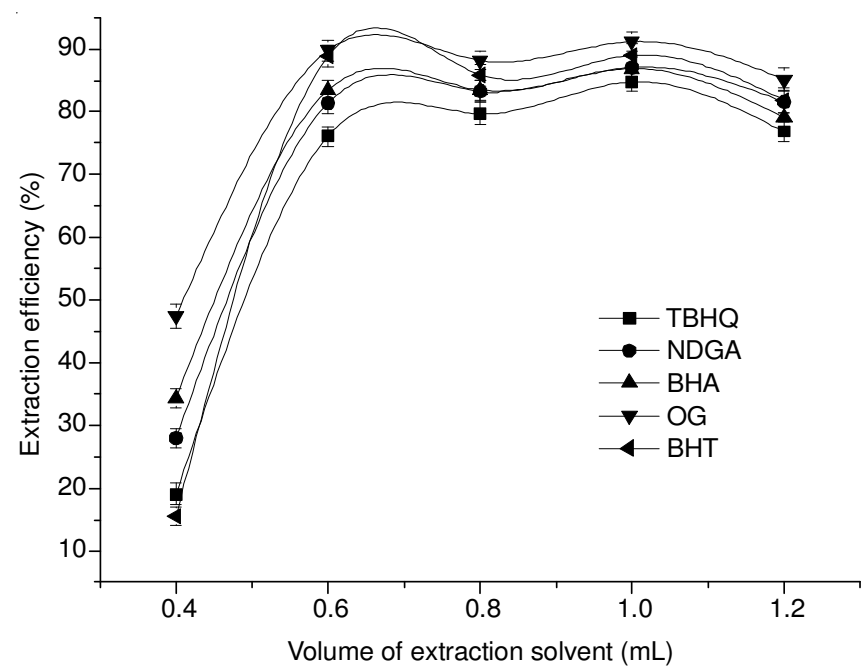

Fig. 3. Effect of extraction solvent volumes on the extraction efficiencies of synthetic phenolic antioxidants by VALLME. Other extraction conditions: sample volume, $5.0 \mathrm{~mL}$; $\mathrm{pH}, 5.0$; vortex time, $30 \mathrm{~s}$

Vortex time: In order to achieve the thorough dispersion of extractant into aqueous phase, the vortex time was individually investigated because the rotational speed has been fixed. Thus, different vortex time $(15,30,60,90,180 \mathrm{~s})$ on the extraction efficiency were evaluated. As can be seen from Fig. 4, no significant effect was discovered when the vortex time ranged from 30 to $180 \mathrm{~s}$, which indicated that the mass transfer might be achieved in only $30 \mathrm{~s}$. This is due to the fact that the contact area between extractant and aqueous phase was greatly enhanced by the existence of dispersive solvent and the vortex agitation, thus greatly increasing the mass transfer rate. Therefore, $30 \mathrm{~s}$ was selected for further experiment. Recently, there are some studies where power ultrasound is successfully used as a means of assisted extraction. It is necessary to make a comparison between ultrasound and vortex mixing. Table-1 indicated that ultrasound extraction need more time to reach considerable extraction efficiency of vortex mixing. The ultrasonic could emulsify more thoroughly, which results in long phase separation times.

Effects of pH: Because all the synthetic phenolic antioxidants are weakly acidic compounds, in order to increase the extraction efficiencies of the synthetic phenolic antioxidants in aqueous solution, the solution should be acidified to prevent them from dissociating during extraction. The effects of $\mathrm{pH}$ 


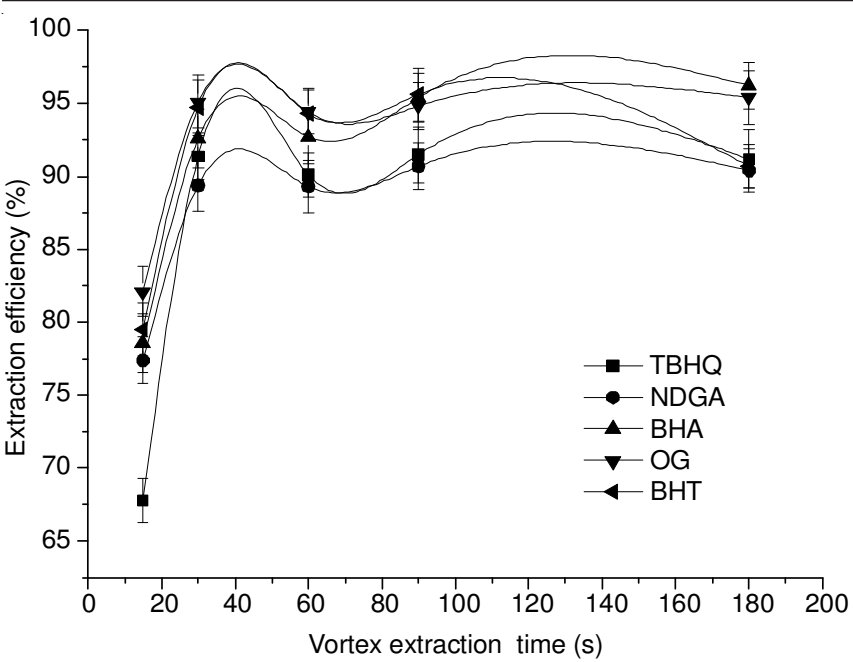

Fig. 4. Effect of vortex time on the extraction efficiencies of synthetic phenolic antioxidants by VALLME. Extraction conditions: sample volume, $5.0 \mathrm{~mL}$; Extraction solvent; $0.6 \mathrm{~mL} \mathrm{pH}, 5.0$

\begin{tabular}{ccc}
\multicolumn{3}{c}{ TABLE-1 } \\
COMPARISON OF EXTRACTION EFFICIENCY \\
BETWEEN VORTEX AND ULTRASOUND \\
\hline Analyte & Vortex $(30 \mathrm{~s})(\%)$ & Ultrasound $(0.5 \mathrm{~h})(\%)$ \\
\hline TBHQ & 97.4 & 88.2 \\
NDGA & 107.0 & 103.1 \\
BHA & 98.8 & 94.8 \\
OG & 90.3 & 87.5 \\
BHT & 93.4 & 90.0 \\
\hline
\end{tabular}

were evaluated in the range of 3-7 by adding appropriate Phosphate Buffer solution to aqueous samples. Fig. 5 shows the results studied within the range of 3-7. The extraction efficiencies of all the analytes increased as the $\mathrm{pH}$ increases from 3 to 5 . When $\mathrm{pH}$ was higher than 5 , the extraction efficiencies decreased with the $\mathrm{pH}$ increase. Hence, $\mathrm{pH} 5$ was selected for further experiment.

Evaluation of method performance: To investigate the method performance of the proposed method for determining synthetic phenolic antioxidants in instant noodle samples, a series of experiments were designed for calculating the parameters under the optimized conditions. Table-2 showed linearity was observed in the range of $10-100 \mu \mathrm{g} \mathrm{mL}^{-1}$ for all the synthetic phenolic antioxidants. All the analytes exhibited good linearity with correlation coefficient $\left(\mathrm{r}^{2}\right)$ ranging from 0.9971 to 0.9996 . The precision of this method was determined by six-time extraction and analysis of spiked aqueous sample. The relative standard deviations (RSD) of the synthetic phenolic antioxidants ranged from 1.7 to $6.4 \%$. The LOD for TBHQ was $3.5 \mathrm{ng} \mathrm{mL}^{-1}$, for NDGA $2.8 \mathrm{ng} \mathrm{mL}^{-1}$, for BHA $3.2 \mathrm{ng} \mathrm{mL}^{-1}$, for $\mathrm{OG} 1.5 \mathrm{ng} \mathrm{mL} \mathrm{m}^{-1}$ and for BHT $6.4 \mathrm{ng} \mathrm{mL}^{-1}$, respectively,

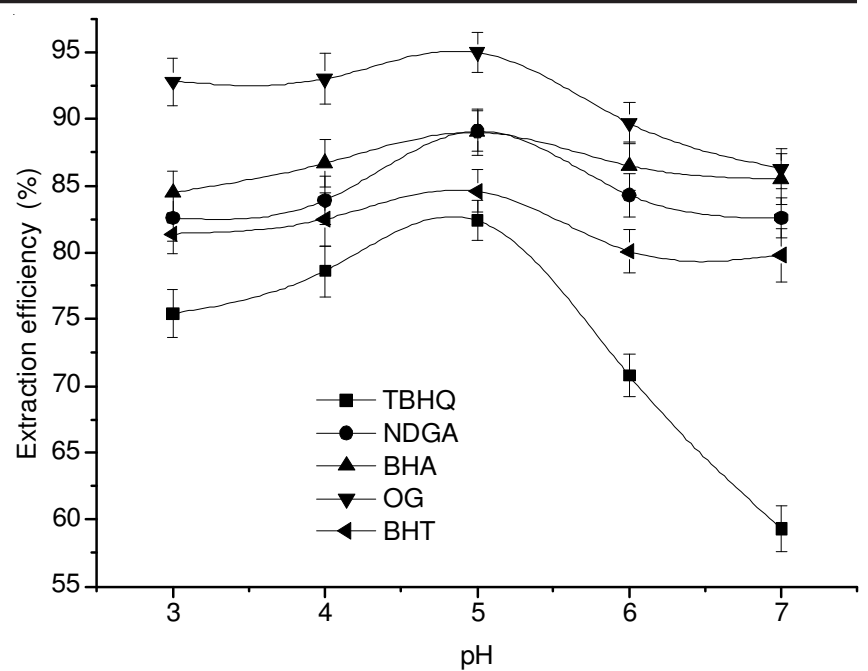

Fig.5. Effect of $\mathrm{pH}$ on the extraction efficiencies of synthetic phenolic antioxidants by VALLME. Extraction conditions: sample volume, $5.0 \mathrm{~mL}$; Extraction solvent, $0.6 \mathrm{~mL}$; vortex time $30 \mathrm{~s}$

\begin{tabular}{ccccc}
\multicolumn{5}{c}{ TABLE-2 } \\
\multicolumn{5}{c}{$\begin{array}{c}\text { PERFORMANCE CHARACTERISTICS } \\
\text { OF THE PROPOSED METHOD }\end{array}$} \\
\hline SPAs & Linearity & $\mathrm{r}^{2}$ & $\begin{array}{c}\text { RSD } \\
(\mathrm{n}=6, \%)\end{array}$ & $\begin{array}{c}\text { LOD } \\
\left(\mathrm{ng} \mathrm{mL}^{-1}\right)\end{array}$ \\
\hline TBHQ & $\mathrm{y}=20.811 \mathrm{x}-0.1419$ & 0.9982 & 5.6 & 3.5 \\
NDGA & $\mathrm{y}=27.632 \mathrm{x}+1.6621$ & 0.9996 & 4.3 & 2.8 \\
BHA & $\mathrm{y}=24.152 \mathrm{x}+9.2961$ & 0.9971 & 3.2 & 3.2 \\
OG & $\mathrm{y}=65.961 \mathrm{x}-5.7954$ & 0.9994 & 1.9 & 1.5 \\
BHT & $\mathrm{y}=14.251 \mathrm{x}+0.1249$ & 0.9997 & 5.8 & 6.4 \\
\hline
\end{tabular}

based on the ratio of signal-to-noise $(\mathrm{S} / \mathrm{N}=3)$. In addition, the experiment indicated that the method has a good ruggedness and could bear a small variance. These parameters indicated that the present approach with high sensitivity and reliability could be used to detect the concentration of synthetic phenolic antioxidants in instant noodle samples.

Analysis of real samples: In this study, all samples of instant noodle which were the most popular brands in Chinese market were obtained from the local supermarket of Kunming city. The samples included the following five types: Jinmailang (Jml), Kangshifu (Ksf), Tongyi (Ty), Huafeng (Hf), Baixiang (Bx). To test the method applicability, the proposed method was used to determine five synthetic phenolic antioxidants in real instant noodle samples. As shown in Table-3, the detected content of synthetic phenolic antioxidants was different in instant noodles manufactured from different companies, ranging from 9 (NDGA) to $15 \mathrm{mg} \mathrm{kg}^{-1}$ (BHT). Other three synthetic phenolic antioxidants were not been detected. The recovery of the five synthetic phenolic antioxidants in the instant noodle

\begin{tabular}{|c|c|c|c|c|c|c|c|}
\hline \multirow{3}{*}{ Sample type } & \multicolumn{6}{|c|}{$\begin{array}{c}\text { TABLE-3 } \\
\text { LEVELS OF SYNTHETIC PHENOLIC ANTIOXIDANTS FOUND IN INSTANT NOODLE SAMPLE }\end{array}$} & \multirow{3}{*}{$\begin{array}{c}\text { RSD } \\
(\mathrm{n}=6, \%)\end{array}$} \\
\hline & \multicolumn{6}{|c|}{ Synthetic phenolic antioxidants $\left(\mathrm{mg} \mathrm{kg}^{-1}\right)$} & \\
\hline & TBHQ & NDGA & BHA & $\mathrm{OG}$ & BHT & Total & \\
\hline $\mathrm{Jml}$ & ND & 10 & ND & ND & 12 & 22 & 2.7 \\
\hline Ksf & ND & 12 & ND & ND & ND & 12 & 4.9 \\
\hline Ty & ND & 9 & ND & ND & 13 & 22 & 4.2 \\
\hline $\mathrm{Hf}$ & ND & ND & ND & ND & 14 & 14 & 3.8 \\
\hline $\mathrm{Bx}$ & ND & 11 & ND & ND & 15 & 27 & 5.6 \\
\hline
\end{tabular}




\begin{tabular}{|c|c|c|c|c|c|}
\hline & $\begin{array}{l}\text { ACCURACY } \\
\text { FOR SAM }\end{array}$ & $\begin{array}{l}\text { T } \\
\text { E METHOD (REI } \\
\text { OLUTION SPIKE }\end{array}$ & $\begin{array}{l}\text {-4 } \\
\text { VE RECOVERIES } \\
\text { DIFFERENT CO }\end{array}$ & $\begin{array}{l}\text { H THEIR RSDs) } \\
\text { NTRATIONS }\end{array}$ & \\
\hline Analyte & Original $\left(\mathrm{mg} \mathrm{kg}^{-1}\right)$ & Added $\left(\mathrm{mg} \mathrm{kg}^{-1}\right)$ & Found $\left(\mathrm{mg} \mathrm{kg}^{-1}\right)$ & Relative recovery (\%) & $\operatorname{RSD}(\mathrm{n}=6, \%)$ \\
\hline \multirow{3}{*}{ TBHQ } & \multirow{3}{*}{0} & 20 & 20.6 & 103.0 & 2.1 \\
\hline & & 30 & 28.9 & 96.3 & 3.8 \\
\hline & & 40 & 38.7 & 96.8 & 3.1 \\
\hline \multirow{3}{*}{ NDGA } & \multirow{3}{*}{8.5} & 20 & 28.6 & 100.5 & 2.8 \\
\hline & & 30 & 36.7 & 94.0 & 6.4 \\
\hline & & 40 & 49.0 & 101.3 & 4.9 \\
\hline \multirow{3}{*}{ BHA } & \multirow{3}{*}{0} & 20 & 18.4 & 92.0 & 5.4 \\
\hline & & 30 & 27.9 & 93.0 & 1.7 \\
\hline & & 40 & 35.8 & 89.5 & 4.1 \\
\hline \multirow{3}{*}{ OG } & \multirow{3}{*}{0} & 20 & 22.1 & 110.5 & 6.4 \\
\hline & & 30 & 28.4 & 94.7 & 5.5 \\
\hline & & 40 & 38.7 & 96.8 & 4.3 \\
\hline \multirow{3}{*}{ BHT } & \multirow{3}{*}{12.7} & 20 & 33.8 & 105.5 & 4.2 \\
\hline & & 30 & 39.9 & 90.7 & 2.8 \\
\hline & & 40 & 51.8 & 97.8 & 3.9 \\
\hline
\end{tabular}

samples spiked at three different concentrations ranged from 77.0 to $103.4 \%$ (Table-4). The typical HPLC chromatograms are shown in Fig. 6.

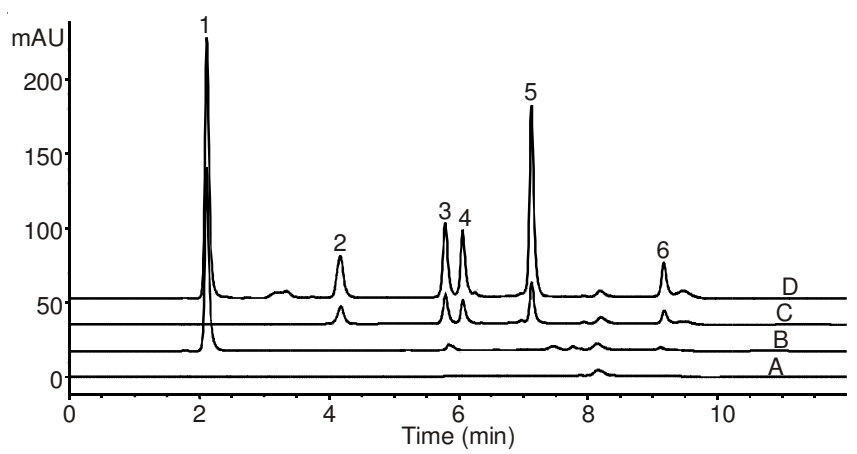

Fig. 6. HPLC-DAD chromatograms (A) blank instant noodle sample, (B) instant noodle sample solution after VA-DLLME, (C) standard (10 $\left.\mu \mathrm{g} \mathrm{mL} L^{-1}\right)$, and (D) instant noodle sample spiked with SPAs $(10 \mu \mathrm{g}$ $\mathrm{mL}^{-1}$ ). Compounds: (1) acetone, (2) TBHQ, (3) NDGA, (4) BHA, (5) OG, (6) BHT. HPLC conditions-gradient separation using methanol and $0.5 \%(\mathrm{v} / \mathrm{v})$ acetic acid; injection volume: $10 \mu \mathrm{L}$; flow rate: $1 \mathrm{~mL} \mathrm{~min}^{-1}$; wavelength: $280 \mathrm{~nm}$

\section{Conclusion}

The present study has developed a method for the analysis of five synthetic phenolic antioxidants in instant noodle samples by using VALLME. The function of vortex mixing could assist the analytes to transfer from aqueous solution to isobutanol phase. Compared with the pretreatment technique mentioned in the instant noodle samples, the VALLME applies isobutanol as extractant can curtail the extraction time, the overall sample pretreatment procedure took about $20 \mathrm{~min}$. For the dispersion of the extractant phase into the aqueous was accomplished using vortex mixing, a mild emulsification procedure, avoiding the drawbacks associated with the application of ultrasound. Considering all of its advantages, VALLME has potential to be applied in the field of synthetic phenolic antioxidants extraction of instant noodle samples.

\section{ACKNOWLEDGEMENTS}

This work was supported by grants from National Innovation Fund for Small and Medium-sized Enterprises (12C26215306449) and Analysis Test Research Center of Kunming University of Science and Technology, Yunnan Province, China.

\section{REFERENCES}

1. I. Fki, N. Allouche and S. Sayadi, Food Chem., 93, 197 (2005).

2. H.C. Grice, Food Chem. Toxicol., 26, 717 (1988).

3. R. Rodil, J.B. Quintana, G. Basaglia, M.C. Pietrogrande and R. Cela, J. Chromatogr. A, 1217, 6428 (2010).

4. M.A. Ruiz, E. García-Moreno, C. Barbas and J.M. Pingarrón, Electroanalysis, 11, 470 (1999).

5. E. Elgin, S. Konyalioglu and E. Kilinc, J. Liquid Chromatogr. Relat. Technol., 35, 1194 (2008).

6. D.W.M. Sin, Y.C. Wong, C.Y. Mak, S.T. Sze and W.Y. Yao, J. Food Compos. Anal., 19, 784 (2006).

7. Y. Xiong and X. Zhang, Chin. J. Chem., 29, 1143 (2011).

8. A. Zafra-Gómez, B. Luzón-Toro, I. Jiménez-Diaz, O. Ballesteros and A. Navalón, J. Pharm. Biomed. Anal., 53, 103 (2010).

9. L. Guo, M.Y. Xie, A.P. Yan and Y.Q. Wan, Anal. Biochem., 386, 1881 (2006).

10. R. El-Rashidy and S. Niazi, J. Pharm. Sci., 68, 103 (1979).

11. D. Djozan and Y. Assadi, Chromatographia, 60, 313 (2004).

12. F.A.O. Olgun, B.D. Ozturk and R. Apak, Food Anal. Methods., 5, 1335 (2012).

13. T.J. Klen and B.M. Vodopivec, Food Chem., 134, 2481 (2012).

14. A. Pukalskas, T.A. van Beek and P. de Waard, J. Chromatogr. A, 1074, 81 (2005).

15. M. Mousavi, E. Noroozian, M. Jalali-Heravi and A. Mollahosseini, Anal. Chim. Acta, 581, 71 (2007).

16. L. Montero, S. Conradi, S.H. Weiss and P. Popp, J. Chromatogr. A, 1071, 163 (2005).

17. M. Rezaee, Y. Assadi, M.-R. Milani Hosseini, E. Aghaee, F. Ahmadi and S. Berijani, J. Chromatogr. A, 1116, 1 (2006).

18. M. Rezaee, Y. Yamini, A. Khanchi, M. Faraji and A. Saleh, J. Hazard. Mater., 178, 766 (2010).

19. M.B. Melwanki and M.R. Fuh, J. Chromatogr. A, 1207, 24 (2008).

20. E. Yiantzi, E. Psillakis, K. Tyrovola and N. Kalogerakis, Talanta, 80, 2057 (2010).

21. M. Chen, Q.H. Xia, M.S. Liu and Y.L. Yang, J. Food Sci., 76, 98 (2011).

22. X.Z. Hu, J.H. Wu and Y.Q. Feng, J. Chromatogr. A, 1217, 7010 (2010). 